\title{
CRESCIMENTO INDUSTRIAL E POĹTICA ECONÔMICA NOS ANOS 1930/40
}

Odair da Cruz Paiva

Doutor em História História Social pela USP; Professor do curso de História da UNINOVE e do Programa de Mestrado em História da UniABC; Pesquisador do Museu da Imigraçã̃o - SP

\section{Resumo}

O objetivo do presente artigo é apontar as interfaces do avanço industrial em São Paulo com relação a dois fatores básicos: a crise da economia cafeicultora, precipitada pelo crash da Bolsa de Valores de Nova Iorque em 1929, e o novo ambiente político engendrado após o golpe de 1930. Ambos fatores possibilitam uma reflexão sobre a importância do papel do Estado como gestor de políticas econômicas e articulador da mudança do padrão de reprodução do capital no país. Serão apresentados alguns apontamentos sobre a criação da Companhia Nitro Química Brasileira de forma a exemplificar a associação entre Estado e capital industrial no período.

Palavras-chave: São Paulo (Estado); industrialização; Getúlio Vargas; Nitro Química; cafeicultura.

\section{Abstract}

This paper aims to point the interfaces of the industrial advancement in São Paulo related to two basic factors: the coffee growing economic crisis precipitated by the crash in New York's Stock Market in 1929, and the new political environment engendered after the 1930 coup. Both factors permit a reflection on the importance of the State role as administrator of economic politics and articulator of the changing in the capital reproduction pattern in the country. It will be showed some appointments on the creation of the Companhia Nitro Química Brasileira [Brazilian Nitro Chemistry Company] by means of exemplifying the association between the State and the industrial capital in the period.

Key words: São Paulo (State); industrialization; Getúlio Vargas; Nitro Chemistry; coffee growing. 
“Aguardavam o Sr. Presidente da República no portão principal da grande fábrica de explosivose produtos químicos, além de seu diretor técnico, o Sr. José Ermírio de Moraes, os diretores desse estabelecimento industrial (...). A visita foi demorada, pois V. Excia. percorreu todo o estabelecimento (...). Em resposta [ao discurso de José Ermírio de Moraes] e manifestando opinião sobre o que fora dado a constatar, o presidente Getúlio Vargas pronunciou o seguinte discurso: "Só tenho motivos para felicitar-me pelo auxílio inicial que o governo do país pode, avisadamente, prestar, para a instalação dessa fábrica. O que acabo de verificar pessoalmente ultrapassou minhas expectativas. Os produtos aqui fabricados são úteis não só à defesa militar do Brasil como à defesa de sua economia..." (Jornal Folha da Manhã, 27-4-1940)

Dessa forma, foi noticiada pela imprensa a inauguração da Companhia Nitro Química Brasileira, em 26 de abril de 1940, no bairro de São Miguel Paulista, em São Paulo. Sua criação inseriu-se num processo a partir do qual a industrialização passaria a ser o carro-chefe da economia paulista, suplantando a hegemonia da cafeicultura. O crescimento das atividades industriais em São Paulo, tema bastante recorrente em estudos sobre as décadas de 30 e 40, apresenta questões importantes e complexas, na medida de sua relação com a mudança do padrão de acumulação capitalista e as novas relações entre o Estado e os empresários.

Nosso intuito, neste artigo, é apontar as interfaces do avanço industrial em São Paulo ligado a fatores que nos remetem, em primeiro lugar, à crise da cafeicultura, precipitada pelo crash da Bolsa de Valores de Nova Iorque, e ao novo ambiente político nos anos 30; nesse ambiente, a política econômica promovida pelo Estado rearticulou os papéis e as funções dos grupos agroexportadores e industriais, de forma a garantir a primazia dos últimos.

Em primeiro lugar, as sucessivas crises de superprodução do café, durante as primeiras décadas da República, foram superadas de forma paliativa por mecanismos de regulação artificial entre a 
produção e a demanda ${ }^{1}$. Compra de excedentes, criação de infra- 1 Há uma vasta literatura sobre essa estrutura de armazenagem e política de desvalorização cambial questão. Sugerimos: PRADO Irí. foram alcumas das formas de intervencão foram algumas das formas de intervenção do Estado para a 233. rocurão sintese interessante regulação artificial entre a oferta e a demanda da produção cafeeira ${ }^{2}$. deste problema, ver ARAUUJ O,

Em razão da intervenção estatal, a produção do café parecia não conhecer limites para sua expansão. Entre 1925 e 1929, o crescimento foi praticamente de $100 \%$, a ponto de as exportações do biênio 1927-1929 absorverem apenas 2/3 do total produzido. Em 1930, o número de cafeeiros plantados chegou a 1,15 bilhão. (FURTADO, 1984:187-8)

Ancorada em um padrão de acumulação agroexportador, a economia brasileira mostrava sua dependência em relação aos mercados externos. Ao mesmo tempo, estava cada vez mais visível a fragilidade desse padrão como sustentáculo do poder político de elites regionais. A partir dos anos 20, a manutenção dos mecanismos de regulação artificial ficou cada vez mais difícil, já que muitos setores da sociedade brasileira, como os tenentes, a classe média e 0 operariado, passaram a questionar a ausência de atendimento de suas demandas na política econômica do Estado brasileiro. A crise econômica em curso nos Estados Unidos, cuja expressão maior foi a bancarrota da Bolsa de Valores de Nova Iorque, em 1929, expôs com mais intensidade os frágeis pilares nos quais se assentava a economia do país.

Estruturadas para atender às necessidades básicas de consumo da população, as indústrias instaladas em São Paulo e no Rio de Janeiro experimentaram um crescimento significativo, tanto em número quanto em volume de mercadorias produzidas. № entanto, não foram beneficiadas por políticas de incentivo ou fomento do Estado, pois, nesse período, ocupavam um lugar subalterno no padrão de acumulação capitalista vigente.

O golpe de 1930 instaurou, paulatinamente nos anos seguintes, novas diretrizes para a economia brasileira, garantindo as bases para um novo padrão de acumulação de capital. O fortalecimento do setor industrial significou também o embate entre projetos políticos, uma nova articulação dos setores dominantes, mudança nas políticas sociais e econômicas do Estado e novas formas de dominação e resistência. A reacomodação dos interesses industriais nas políticas de desenvolvimento econômico no período 
representou um momento complexo nas relações entre o Estado e a burguesia cafeicultora, momento este agravado pela situação social instável do país, após o Golpe de 1930.

Em Evolução Industrial do Brasil, de Roberto Simonsen, encontramos a formulação de um modelo industrial que permitiu uma nova rearticulação entre o campo e a cidade, dando à burguesia deste setor a capacidade de coordenação e controle que, segundo ele, havia sido perdida com a crise do modelo agrário-exportador:

O crescimento de centros manufatureiros e a diminuição do interesse pelas lavouras de alimentação ocasionam um constante encarecimento da vida, para os operários da cidade (...) temos que levar à agricultura toda messe de conhecimentos da técnica e da organização, facilitando sua estruturação em bases cientificamente traçadas e, em conseqüência, proporcionando maiores remunerações aos que a ela se dedicam. Pela produção em massa de gêneros de primeira necessidade, $\mathrm{e}$ pela distribuição, sob critério rigorosamente econômico, baratearíamos o seu custo, proporcionando também maiores proventos aos que se entregam a esse labor. De outro lado, fortaleceríamos o salário real de todos os que vivem nos grandes centros. Essa política teria que ser feita paralelamente a uma intensa industrialização do país. E quanto mais se aperfeiçoam os processos de trabalho da terra, menor será o número de colonos que necessitaremos para uma determinada produção agnícola... (SIMONSEN, 1973:187)

Assim, a intensificação do processo de industrialização a partir dos anos 30 representou um movimento de transformação significativa, não apenas na economia, mas também na dinâmica das relações sociais no país. Ao representar o embate entre diferentes projetos, a industrialização apontou as dissenções entre os blocos que compuseram o poder naquele período. De Decca (1980) 
demonstrou que esse debate foi além de uma querela entre os setores dominantes. Os interesses industriais emergiram como uma proposição vencedora; nessa perspectiva, a fragilidade do modelo agrário-exportador, decantada pela historiografia como a crise dos anos vinte, começava a estruturar uma nova modalidade combinada com o modelo de substituição de importações.

A criação do Instituto Brasileiro do Café e do Instituto do Açúcar e do Álcool visando à regulação das atividades agroexportadoras expõe um exemplo claro dessa combinação. Possivelmente, o melhor exemplo da relação entre indústria e esse controle tenha sido a legislação trabalhista que, a partir dos anos 30, representou uma forma de racionalização e concentração do poder do capital sobre o trabalho. Assim, os antigos grupos de interesse, voltados para o padrão agroexportador, mantiveram-se representados nas políticas econômicas do período, mas tiveram de conviver com novos grupos emergentes que tinham, nas atividades industriais, sua base de sustentação política.

Os anos 30 foram um período cujos conflitos de interesses entre esses dois grupos tiveram de ser administrados, uma vez que, mesmo perdendo espaço para as atividades industriais, o setor agroexportador não deveria ser desamparado; ele representava, apesar do refluxo dos mercados internacionais nos anos 30, a principal fonte de recursos do país e o esteio fundamental para os investimentos na infra-estrutura industrial.

No projeto de Simonsen, uma nova rearticulação campocidade, capitaneada pela indústria, supunha um sistema coordenado: campo modernizado e agregador de menor quantidade de mão-de-obra, produtivo e expulsor dos trabalhadores excedentes. Por outro lado, os trabalhadores urbanos encontrariam uma alimentação mais barata, e a indústria pagaria menores salários e se beneficiaria de uma mão-de-obra abundante. A base latifundiária e os setores sociais que a sustentavam perderiam sua hegemonia nesse novo cenário da economia brasileira. Pela percepção de Simonsen, observamos uma certa cisão de interesses entre a burguesia industrial e os setores agrários tradicionais, ao mesmo tempo em que o campo deixava de ser pensado como centro articulador das atividades econômicas. Nesse contexto, identidade e função seriam reorientadas a partir dos interesses urbanos e industriais. 
O crescimento das atividades industriais no conjunto da economia foi percebido já no transcurso dos anos 30. Um confronto entre estatísticas sobre a produção agrícola e industrial, a partir deste período, ealguns dados sobre o nível de emprego apontam com clareza a hegemonia econômica que este último teria sobre o primeiro, tanto na geração de capital quanto na produção de mercadorias.

Produção Agrícola e Manufatureira em São Paulo: 1931-1938 (em milhares de contos de réis)

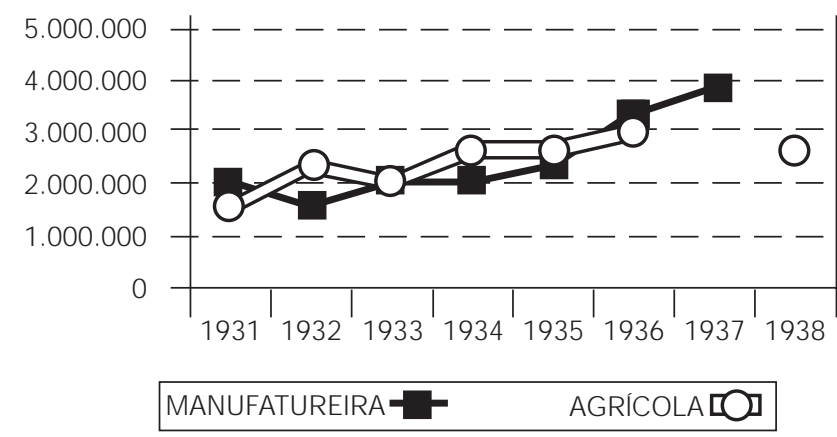

Fonte: Boletim do Departamento Estadual de Estatística, 1942

Com os dados do quadro acima, percebemos uma expressiva recuperação nos valores da produção agrícola, a partir de 1932; particularmente, se considerarmos a média de valores de 1932 a 1936, encontraremos uma evolução percentual da ordem de 59\% se comparada a 1930. Em 1936, o valor da produção industrial ultrapassa o da produção agrícola; no plano nacional - de acordo com dados dos anos 20, 30 e da primeira metade dos anos 40 - , a indústria teve melhor desempenho, como demonstra também o quadro a seguir:

Taxas de Crescimento da Produção Física na Agricultura e Indústria no Brasil - 1920-1945

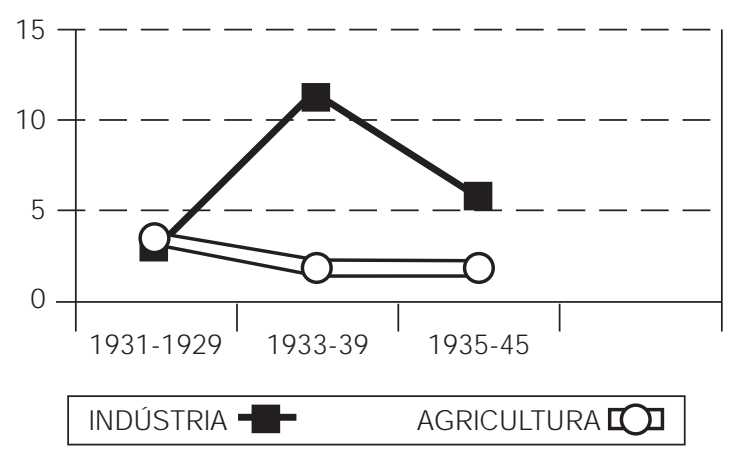

Fonte: HOLLANDA e GRAHAM, 1982:57 
As taxas de crescimento da indústria paulista revelavam um mercado de trabalho em ascensão que, segundo Paul Singer (In HOLANDA, 1986:17), apareceu na indústria têxtil, onde o capital industrial se reproduziu em proporções mais significativas, no período entre 1932 e 1939. Esse crescimento girou em torno de 13\% a.a., enquanto o conjunto da indústria de transformação cresce $10 \%$ a.a., aumentando a oferta de empregos.

Segundo dados extraídos dos censos gerais de 1920 e 1940 por Zélia Lopes da Silva (1983:29), entre 1920 e 1940, o número de trabalhadores na indústria em São Paulo sobe de 83.889 para 254.771, um aumento percentual de $204 \%$. Outro dado significativo colhido pela autora é o da evolução do nível de emprego nos principais ramos industriais, entre 1928 e 1937, no Estado de São Paulo. Em valores percentuais, temos:

Evolução do Nível de Emprego na

Cidade de São Paulo 1928/37

\begin{tabular}{|c|c|}
\hline RAMO & $\%$ \\
\hline Metalurgia & 365 \\
\hline Construção e Mobiliário & 224 \\
\hline Gráficos & 165 \\
\hline Produtos Químicos & 140 \\
\hline Têxtil e Vestuário & 133 \\
\hline Alienação & 94 \\
\hline
\end{tabular}

Fonte: SILVA (1983:41-2)

No decorrer dos anos 30 e 40, a industrialização se consolida como alternativa viável ao processo de acumulação capitalista no país. Amparado por políticas de cunho protecionista, o governo Vargas procurou incentivar a formação de um parque industrial voltado para a produção de bens de capital, insumos e matérias-primas estratégicas.

Acriação da Cia. Nitro Química Brasileira é exemplar, e não teria sido possível sem uma intensa articulação entre os interesses de dois grupos empresariais paulistas: de um lado, Wolff Klabin (Klabin, Irmãos e Cia), e de outro, José Ermírio de Moraes (S.A. 
Fábrica Votorantim). Esta associação deu origem à Cia. Nitro Química Brasileira com o objetivo de fabricar e comercializar produtos químicos e seus derivados (ácido sulfúrico e nítrico, sulfato de sódio, éter e colódio) e têxteis, como seda artificial. Entre estes produtos, alguns poderiam ser destinados a um esforço bélico, como a fabricação de T.N.T.

A história da Nitro Química começou cinco anos antes quando, em 1935, Klabin tomou conhecimento da desativação da Tubize Chantillon Corporation, no Estado de Virgínia, EUA Essa fábrica produzia, entre outros produtos químicos, o fio sintético de qualidade que se assemelhava à seda, o raiom tipo Chandornnet, utilizado na indústria de fiação de tecidos. Com a crise econômica após o crash da Bolsa de Nova Iorque, a fábrica foi obrigada a encerrar suas atividades. Klabin e Ermírio de Moraes realizaram um projeto ambicioso: trazer - literalmente - a fábrica estadunidense para o Brasil, desmontando suas instalações na sede, em Hopewell, na Virgínia, remontando-a no então longínquo distrito de São Miguel Paulista, na capital de São Paulo. (FONTES, 1997:31)

O crescimento da indústria têxtil no Brasil, desde os anos 30, representava possibilidade de alta lucratividade. Atransferência das instalações da Tubize para o Brasil foi uma forma de enfrentamento mais efetivo com um dos grandes do setor: o grupo Matarazzo. Esse grupo havia iniciado a produção do fio raiom no Brasil, em 1926, e monopolizava sua produção. Somente em 1933, a empresa Rhone Poulenc-Rhodia, de origem francesa, iniciou a produção do raiom em sua fábrica instalada no município de Santo André, SP. A existência de apenas duas companhias produtoras do raiom, num mercado de possibilidades crescentes, levou os dois grupos a realizarem o projeto.

Em discurso proferido na cerimônia de inauguração da Nitro Química, José Ermírio de Moraes criticou o monopólio das indústrias do setor, chamando para a Nitro a responsabilidade patriótica da empresa na defesa da indústria nacional:

É com a exata compreensão do seu valor econômico e da importância da missão que ela desempenha sentirá Vossa Excelência como chefe de Estado e como patriota esclarecido, que é um 
dever patriótico ampará-la contra os "dumpings" perigosos e dissolventes, cuja única finalidade reside na destruição do que custou tanto a construir e a por de pé. As nações sem celulose e nitro celulose são nações indefesas, mal preparadas para as indústrias de paz e da guerra. Como brasileiro, muito mais do que como industrial, tenho a certeza de que Vossa Excelência continuará estimulando e defendendo todos aqueles que se dedicarem sinceramente à causa do fortalecimento econômico do Brasil...

3 J ornal O Estado de São Paulo. edição de 27 de abril de 1940 .

A indústria da tecelagem representava, desde as primeiras décadas do século XX, um dos setores mais dinâmicos da indústria paulista. Segundo recenseamento realizado pela Secretaria da Agricultura, Indústria, Comércio e Obras Públicas, em 1927, ela aparecia como um dos principais setores industriais, tanto do ponto de vista do número de estabelecimentos quanto de operários na Capital e, sem dúvida, um dos ramos industriais mais fortes e com presença significativa em muitas cidades do interior do Estado. São Paulo contava, no fim dos anos 20, com 155 empresas do ramo. Desse universo, 45 delas empregavam mais de trezentos trabalhadores. Um setor bastante concorrido, contando com companhias de porte como o grupo Matarazzo, Crespi, Jafet e Alpargatas.

ANitro Química tinha, na produção do raiom, a perspectiva de concorrer como fornecedora de matéria-prima para um segmento específico desse mercado - o da tecelagem de fibras sintéticas - e, ao mesmo tempo, de atuar na produção de outros tipos de produtos químicos e derivados. Portanto, a Nitro possuía interesses de mercado que extrapolavam o setor têxtil.

O custo da transferência da fábrica de Hopewell para São Miguel Paulista foi vultoso. Klabin e Moraes fizeram uma associação com o Banco Comércio e Indústria de São Paulo; um grupo de quatorze empresários do setor também se associou a eles. Entretanto, o grande parceiro do empreendimento foi o governo Vargas. Por meio da ligação com o Estado, os empresários objetivaram a isenção de direitos alfandegários que viabilizaria a transferência das instalações da fábrica a um custo menor; em contrapartida, ofereceriam a produção de materiais como ácido 
sulfúrico, nitrocelulose que, embora utilizados na produção do raiom, poderiam ter outras finalidades, inclusive militares.

Logo após a constituição do acordo com a Tubise, a imprensa da época noticiou a entrada do Estado no negócio: "Há notícias de que o governo federal, por decreto, concedeu isenção de direitos de importação a todo o equipamento, utilizado na montagem da Nitro Química, que entrasse no país até 31-12-1935. Esse equipamento pesava 18 mil toneladas e foi trazido ao país por navios do Lloyd Brasileiro..." (apud ROCHA, 1992:54)

Favorecida por um contexto internacional, no qual o refluxo das economias capitalistas dos países centrais (Europa e Estados Unidos) foi marcado pela depressão econômica do início dos anos 30 e, em seguida, pela eclosão da II Guerra Mundial, a indústria no Brasil pode, em certa medida, ampliar-se e diversificarse em quadro de pouca concorrência externa. Ao contrário do que ocorreu nas primeiras décadas da República, os grupos industriais mantiveram, sob o governo Vargas, fortes laços políticos, beneficiando-se de isenções de impostos de importação de máquinas e insumos e, principalmente, de uma política de controle das atividades sindicais, além da nacionalização da mão-de-obra.

Assim, a mudança do perfil da industrialização em São Paulo coincide com transformações no quadro político e institucional do país na passagem dos anos 20 para os 30. Do plano secundário no processo de acumulação capitalista, a indústria emergiu, de maneira paulatina, para um lugar de destaque na economia brasileira.

Por fim, a criação da Nitro Química nos propicia um exemplo efetivo da conjunção entre os interesses de grupos industriais que se beneficiaram com a crise do padrão agroexportador, sustentáculo da economia brasileira durante todo o período da República Velha, e com as novas orientações do Estado para o desenvolvimento econômico do país. Ainda que essa conjunção já tenha sido traçada em linhas gerais pela historiografia do período, acreditamos que pesquisas sobre as grandes empresas, surgidas nos anos 30, ou mesmo as que já estavam instaladas desde 1920, possam deslindar elementos importantes dessa relação e apontar para outros elementos dessa nova fase do processo de industrialização em São Paulo. 


\section{Referências bibliográficas}

DE DECCA, Edgar. O Slêncio dos Vencidos. São Paulo: Brasiliense, 1980.

FONTES, Paulo. Trabalhadores. Nitro Química: a fábrica e as lutas operárias nos anos 50. São Paulo: Annablume, 1997.

FURTADO, Celso. Formação Econômica do Brasil. São Paulo: Editora Nacional, 1984.

HOLLANDA Filho, Sérgio Buarque de; GRAHAM, Douglas $\mathrm{H}$. Migrações Internas no Brasil: 1872-1970. São Paulo: Global, 1982.

PAIVA, Odair da Cruz. Caminhos Cruzados. São Paulo: 2000. Tese (Doutorado em História Social) - Departamento de História, Faculdade de Filosofia, Letras e Ciências Humanas. Universidade de São Paulo.

ROCHA, Antonia Aziz. O Bairro à Sombra da Chaminé: um estudo sobre a formação da classe trabalhadora da Companhia Nitro Química de São Miguel Paulista (1935-1960). São Paulo: 1992. Dissertação (Mestrado em Filosofia da Educação) - Pontifícia Universidade Católica de São Paulo.

SÃO PAULO. Boletim do Departamento Estadual de Estatística. São Paulo, n. 7, julho de 1942.

SILVA, Zélia Lopes da. A Face Oculta da Reprodução (um estudo sobre os trabalhadores rurais em São Paulo: 1930/34) Dissertação (Mestrado em História) Instituto de Filosofia e Ciências Humanas, Universidade Estadual de Campinas, 1983.

SIMONSEN, Roberto C. Evolução Industrial do Brasil. São Paulo: Ed. Nacional: Universidade de São Paulo, 1973.

SINGER, Paul. Interpretação do Brasil: Uma experiência histórica de desenvolvimento. In: HOLANDA, Sérgio Buarque de (Org.) História Geral da Civilização Brasileira. São Paulo: Brasiliense, 1986, v. 11. 
